\title{
PREVALENCIA SEROLÓGICA LA ENFERMEDAD DE NEWCASTLE Y BRONQUITIS EN CODORNICES (Coturnix coturnix) EN EL ÁREA METROPOLITANA DE CÚCUTA Y MUNICIPIOS ALEDAÑOS
}

Por:

Leonardo Hernández Corredor 1, Hernando Mateus Ramírez ${ }^{2}$ José Eduardo Contreras Salamanca ${ }^{3}$, Gerson Oriel Nieto Sepúlveda ${ }^{4}$

\section{RESUMEN}

En los municipios de Cúcuta, Chinácota, Los Patios, Bochalema y Villa del Rosario, un total de 12 granjas fueron estudiadas para determinar la prevalencia de las enfermedades de Newcastle y Bronquitis Infecciosa en codornices, debido a la escasa información que sobre éstas enfermedades en ésta especie. Se determinó una prevalencia serológica de $50.9 \%$ para Newcastle y de $32.7 \%$ para Bronquitis Infecciosa. Por lo que discute la presencia de estas dos entidades en esta región y los posibles mecanismos de control.

\section{ABSTRACT}

In the municipalities of Cúcuta, Chinácota, Los Patios, Bochalema and Villa del Rosario, a total of 12 farm was studied to determine the prevalence of the disease of Newcastle and Infectious Bronchitis in quails, due to the scarce information that it has more than enough these illnesses in this species. A prevalence of $50.9 \%$ was determined for Newcastle and of $32.7 \%$ for Infectious Bronchitis. For what the presence of these two entities discusses in this region and the possible control mechanisms.

Palabras claves: Prevalencia, serología, Newcastle, Bronquitis Infecciosa, Codornices, (Coturnix cortinix).

\section{INTRODUCCIÓN}

En la crianza de aves, la avicultura (de gallinas ponedoras, pollos de engorde y reproductoras) siempre ha tenido un gran apoyo investigativo, siendo una industria en la cual se aplican planes de bioseguridad. La coturnicultura siempre fue vista como una explotación para pequeños granjeros, por lo que ha estado algo relegada de esas investigaciones, es por ello que en el mundo existen muy pocos planes vacunales para las codornices (Coturnix coturnix) y siempre han tratado de aplicarse los mismos que se implementaron en gallinas y pollos. Adicionalmente, algunos Asesores Técnicos nunca se han preocupado por buscar aspectos técnicos de referencias en codornices (Hernández, 2002). En el Departamento Norte de Santander, la coturnicultura ha venido creciendo en los últimos años en forma vertiginosa, por lo que están apareciendo problemas sanitarios en los planteles. No se manejan planes de bioseguridad, no existen planes de vacunación, ni de diagnóstico de enfermedades.

La enfermedad de Newcastle (NDV) es una importante infección viral en aves que puede causar perdidas en la industria avícola (Paulillo et al., 1982; Paulillo y Doretto Junior, 2000). La NDV se encuentra en la lista A de las enfermedades en la "Oficina Internacional de Epizootias" OIE (2001).

En cuanto a codornices estudios realizados por el Centro de Investigaciones de Salud Animal del Instituto Colombiano Agropecuario (CEISA) en Cundinamarca y Tolíma se infectaron unas aves con el virus de Newcastle, llegando a la conclusión que la codornices no sufren la enfermedad pero son portadoras (Revista Avicultores, 2002), Kaleta and Baldauf, (1979) citado por Alexander, (1995) concluyeron que además de las especies domésticas, la infección natural o experimental se demostró en por lo menos 236 especies de 27 de los 50 órdenes de aves. Las especies de aves acuáticas son las más resistentes, mientras que las más susceptibles son las gregarias que forman parvadas permanentes o temporales. El virus de la

\footnotetext{
1 Ingeniero de Producción Animal, Profesor U.F.P.S. Lhdezco@latinmail.com

2 Médico Veterinario. Profesor U.F.P.S

3 Zootecnista Profesor U.F.P.S.

${ }^{4}$ Médico Veterinario-Zootecnista, B.L.C. Especialista en Anatomopatología ICA, Profesor U.F.P.S.
} 
Prevalencia serológica la enfermedad de newcastle y bronquitis en codornices (Coturnix coturnix) en el Área Metropolitana de Cúcuta y municipios aledaños

enfermedad de Newcastle es capaz de infectar sin causar mortalidad severa en aves con alto nivel de inmunidad, pudiendo afectar gallinas domésticas, pavos, faisanes, codornices, palomas y aves silvestres con o sin signos de la enfermedad; por lo tanto los reservorios del virus son múltiples (Ziedler y Hlinak, 1983).

\section{MATERIALES Y MÉTODOS}

El estudio se realizó en 12 granjas coturnicolas ubicadas en los municipios de Cúcuta, Chinácota, Los Patios, Bochalema y Villa del Rosario, de las cuales 36.900 aves se encuentran un 80.71 \% $\quad(29.782$ aves) en postura, un $14.30 \%$ (5.280 aves) en la etapa de cría y un $5.65 \%$ (2.088 aves) en reproducción. En la región de estudio la línea de codornices que más sobresale es la Japónica con un $77.5 \%$ (28.600 aves) y la Coreana con un $22.5 \%$ (8.300 aves) y en solo un $16.6 \%$ de los predios utiliza vacunación en su explotación coturnícola, el $83.3 \%$ no coloca ningún tipo de vacuna a las aves.

Tamaño de la Muestra

Para el estudio, el tamaño de la muestra se obtuvo mediante la siguiente fórmula (Centro Panamericano de Zoonosis, 1973):

Tamaño de la muestra $(\mathrm{n})=\frac{\mathrm{N}^{*} \mathrm{z}^{2}{ }^{*} \mathrm{p}^{*} \mathrm{q}}{\mathrm{e}^{2}(\mathrm{~N}-1)+\mathrm{z}^{2 *} \mathrm{p}^{*} \mathrm{q}}$

Donde se asumió la Probabilidad de que ocurra el evento ( $p=0.83$ para Newcastle y 0.87 para Bronquitis Infecciosa) y la Probabilidad de que no ocurra el evento ( $q=0.17$ para Newcastle y 0.13 para Bronquitis Infecciosa, un Grado de Error máximo $0.05 \%$, y un Nivel de confianza a un $95 \%$

De lo anterior se obtuvo un tamaño de muestra de " $\mathrm{n}$ " = 218 para Newcastle y $" n "=177$ para Bronquitis Infecciosa, posteriormente se calcularon las fracciones muestrales " $f$ " $n / \mathrm{N}$ (Centro Panamericano de Zoonosis,
1973). En las granjas los animales se seleccionaron al azar para la toma de la muestra, la cual después de centrifugar, se realizaron los análisis de Inhibición de la Hemoaglutinación (HI) para Newcastle y ELISA para Bronquitis Infecciosa.

\section{RESULTADOS Y DISCUSIÓN}

La evaluación serológica para la enfermedad de Newcastle, permitió establecer que de 218 sueros tomados 111 sueros (50.9\%) eran reactores positivos, tomando como base los títulos mayores e iguales a 1 : 4 (De Rosa, 2002; Mateus, 2002). En el Cuadro 1 se observa la distribución de título para la prueba de HI de la enfermedad de Newcastle por granja. Siendo la granja número 4, la 6, la 7, la 11 y la 12 que presentan el $100 \%$ de los títulos positivos, la granja que más disparidad presenta en cuanto a títulos es la granja 9 de 35 sueros negativos (menores e iguales a $1: 2$ ), presenta 9 sueros con títulos positivos y la grania número 3 presenta todos los títulos negativos.

En el Cuadro 2 se observa la distribución de los título para la prueba de Inhibición de la Hemoaglutinación (HI) por municipios. Siendo el municipio de Los Patios, el de mayor número de sueros positivos (>1: 4), con 33 sueros positivos de 38 sueros recolectados, seguido por el municipio de Chinácota con 27 sueros positivos de 40 sueros recolectados, en el municipio de Villa del Rosario de 90 sueros recolectados 36 son positivos, en el municipio de Bochalema de 43 sueros recolectados 8 son positivos y por último el municipio de Cúcuta, de 7 sueros recolectados 7 son positivos, pero la muestra en éste municipio es muy pequeña. La prevalencia serológica estimada de $50.9 \%$, según el margen de error asumido de (5\%) no sería mayor a $51.28 \%$, de acuerdo con el intervalo de confianza indicaría que la prevalencia estimada se encontraría entre $50.52 \%$ y $50.9 \%$ ( $P \leq 0.05)$.

En el cuadro 3 se observa la distribución de sueros según la evaluación por la prueba de Inmunoensayo Asociado a Enzima (ELISA) para la enfermedad de 
Prevalencia serológica la enfermedad de newcastle y bronquitis en codornices (Coturnix coturnix) en el Área Metropolitana de Cúcuta y municipios aledaños

Bronquitis Infecciosa, con la cual se permitió establecer que de 177 sueros tomados 58 sueros (32.7\%) eran reactores positivos, tomando como positivos los títulos de mayores e iguales a 1500 (Villegas y Avellaneda, 1992). Cuadro 1.

El municipio de Bochalema, el de mayor número de sueros positivos (> 1500), con 24 sueros positivos de 40 sueros recolectados, es de destacar que solo se muestreo una sola granja en éste municipio, seguido por el municipio de Chinácota con 17 sueros positivos de 39 sueros recolectados, en el municipio de Villa del Rosario que fue el que más muestreo de 66 sueros recolectados 11 son positivos, en el municipio de Los Patios de 25 sueros recolectados 6 son positivos y por último el municipio de Cúcuta, de 7 sueros recolectados los 7 son negativos, pero la muestra en éste municipio es muy pequeña. La prevalencia serológica estimada de $32.7 \%$, según el margen de error asumido de (5\%) no sería mayor a $33.11 \%$, de acuerdo con el intervalo de confianza indicaría que la prevalencia estimada se encontraría entre $32.29 \%$ y $32.7 \%$ (P£ 0.05). Cuadro 2.

Cuadro 1. Distribución de suero según el título, para la prueba de HI de la enfermedad de Newcastle.

\begin{tabular}{|c|c|c|c|c|c|c|c|c|c|c|c|c|c|c|c|c|}
\hline Granjas & Municipio & Muestras & \multicolumn{13}{|c|}{ Títulos } & Total \\
\hline & $*$ & & 0 & $1: 2$ & 1:4 & $1: 8$ & $1: 16$ & $1: 32$ & $1: 64$ & $1: 128$ & $1: 256$ & $1: 512$ & $1: 1024$ & 1:2046 & 1:4096 & $\geq 1: 4$ \\
\hline 1 & $\mathrm{~V} / \mathrm{R}$ & 19 & 1 & 12 & 5 & 1 & - & - & - & - & - & - & - & & - & 6 \\
\hline 2 & $\mathrm{~V} / \mathrm{R}$ & 24 & - & 17 & 4 & 1 & 1 & - & - & - & - & 1 & - & - & - & 7 \\
\hline 3 & $\mathrm{~V} / \mathrm{R}$ & 24 & 4 & 20 & - & - & - & - & - & - & - & - & - & - & - & 0 \\
\hline 4 & $\mathrm{~V} / \mathrm{R}$ & 7 & - & - & - & - & - & - & - & 5 & 2 & - & - & - & - & 7 \\
\hline 5 & $\mathrm{~V} / \mathrm{R}$ & 16 & - & - & - & - & - & - & - & 6 & 5 & 3 & 1 & 1 & - & 16 \\
\hline 6 & Chi & 15 & - & - & - & - & - & - & - & 2 & 7 & 6 & - & - & - & 15 \\
\hline 7 & Chi & 7 & - & - & - & - & - & - & 1 & 1 & 2 & 3 & - & - & - & 7 \\
\hline 8 & Chi & 18 & 11 & 2 & 3 & 1 & - & - & 1 & - & - & - & - & - & - & 5 \\
\hline 9 & Boc & 43 & 30 & 5 & 4 & 2 & - & 1 & - & - & - & - & - & - & 1 & 8 \\
\hline 10 & LP & 29 & - & - & - & - & - & - & 1 & - & 6 & 8 & 5 & 3 & 6 & 29 \\
\hline 11 & LP & 9 & 3 & 2 & 4 & - & - & - & - & - & - & - & - & - & - & 4 \\
\hline 12 & Cúc & 7 & - & - & - & - & - & - & - & 2 & 2 & 1 & 1 & 1 & - & 7 \\
\hline Total & & 218 & 49 & 58 & 20 & 5 & 1 & 1 & 3 & 16 & 24 & 22 & 7 & 5 & 7 & 111 \\
\hline
\end{tabular}

Fuente: Autores *V/R: Villa del Rosario; Chi: Chinácota; Boc: Bochalema; LP: Los Patios; Cúc: Cúcuta.

Cuadro 2. Distribución de sueros por municipios según la dilución de HI, para Newcastle.

\begin{tabular}{|c|c|c|c|c|c|c|c|c|c|c|c|c|c|c|c|c|}
\hline Municipio & Muestras & \multicolumn{10}{|c|}{ Títulos } & \multicolumn{10}{c|}{ Total } \\
\hline & & 0 & $1: 2$ & $1: 4$ & $1: 8$ & $1: 16$ & $1: 32$ & $1: 64$ & 128 & $1: 256$ & $1: 512$ & $1: 1024$ & $1: 2046$ & $1: 4096$ & $\geq 1: 4$ \\
\hline $\begin{array}{c}\text { Villa del } \\
\text { Rosario }\end{array}$ & 90 & 5 & 49 & 7 & 2 & 1 & - & - & 11 & 7 & 4 & 1 & 1 & - & 36 \\
\hline Chinácota & 40 & 11 & 2 & 3 & 1 & - & - & 2 & 3 & 9 & 9 & - & - & - & 27 \\
\hline Bochalema & 43 & 30 & 5 & 4 & 2 & - & 1 & - & - & - & - & - & - & 1 & 8 \\
\hline Los Patios & 38 & 3 & 2 & 4 & - & - & - & 1 & - & 6 & 8 & 5 & 3 & 6 & 33 \\
\hline Cúcuta & 7 & - & - & - & - & - & - & - & 2 & 2 & 1 & 1 & 1 & - & 7 \\
\hline Total & 15 & 49 & 58 & 20 & 5 & 1 & 1 & 3 & 16 & 24 & 22 & 7 & 5 & 7 & 111 \\
\hline
\end{tabular}

Fuente: Autores. 
Prevalencia serológica la enfermedad de newcastle y bronquitis en codornices (Coturnix coturnix) en el Área Metropolitana de Cúcuta y municipios aledaños

Cuadro 3. Distribución de suero según los títulos de ELISA, por municipios.

\begin{tabular}{|c|c|c|c|c|c|}
\hline Municipio & Muestras & \multicolumn{3}{|c|}{ Títulos } & Total \\
\hline & & $<1500$ & $1500-5500$ & $>5500$ & $>1500$ \\
\hline Villa del Rosario & 66 & 55 & 11 & - & 11 \\
\hline Chinácota & 39 & 22 & 14 & 3 & 17 \\
\hline Bochalema & 40 & 16 & 21 & 3 & 24 \\
\hline Los Patios & 25 & 19 & 3 & 3 & 6 \\
\hline Cúcuta & 7 & 7 & - & - & 0 \\
\hline Total & 177 & 119 & 49 & 9 & 58 \\
\hline
\end{tabular}

\section{CONCLUSIONES}

El muestreo serológico realizado, permitió comprobar, la presencia de títulos de Newcastle en las codornices, lo cual se corroboró con estudios histopatológicos realizados por el Doctor Gerson Nieto del CEISA-ICA Bogotá, estando en contraposición a los estudios realizados en los Departamentos de Cundinamarca y del Tolima, con los cuales se concluyó que las codornices eran resistentes a la enfermedad de Newcastle (Revista Avicultores, 2001), pero si se acepta que las codornices (Coturnix coturnix) son portadoras del virus de acuerdo a lo reportado por Lancaster y Alexander (1966), Paulillo y Doretto Junior et al (2000).

En la epidemia de Centroamérica en el año 2001, se presentaron mortalidades en granjas de reproductoras de codornices (Coturnix coturnix), por lo que se concluyó la necesidad de implementar planes vacunales en codornices (Morella De Rosa, 2002).

En la mayoría de las granjas coturnícolas encuestadas opinaban que es muy común la disminución de la postura en las codornices (Coturnix coturnix) mayores a 20 semanas, pero en comunicación personal con la Doctora Morella De Rosa (2002) y lo observado en campo con el Doctor Hernando Mateus R., cuando las codornices (Coturnix coturnix) presentan problemas respiratorios leves, existe retracción ovárica, coloración blanquecina de la cáscara de los huevos y baja en postura, el coronavirus que produce la enfermedad de Bronquitis Infecciosa, puede evidenciar la sintomatología, al igual que lo reportado por Allred et al. (1973).
En relación con las enfermedades de Newcastle y Bronquitis Infecciosa, es necesario realizar seguimientos clínico-serológicos y patológicos, con el fin de recomendar - no, la aplicación de las vacunas contra las enfermedades, siempre y cuando la situación lo amerite, la falta de registros sanitarios y la creencia de algunos Asistentes Técnicos a que las codornices (Coturnix coturnix), son muy resistentes a las enfermedades, hacen difícil los seguimientos clínico-serológicos.

\section{REFERENCIA BIBLIOGRÁFICA}

Alexander, D. J. 1995. Newcastle. World Poultry $N^{\circ}$ 38. pp. 97-104.

Allred, N., Raggi, L. and Lee, G. 1973. Susceptibility and resistance of pheasants, starlings and quail to three respiratory disease of chickens. Calif. Fish Game 59. pp. 161-167.

Calnek, B. W. 1995. Enfermedades de las aves. Universidad Estatal de lowa. Watt Publish. pp. 575-627.

Centro Panamericano de Zoonosis. 1973. Bioestadística, procedimientos para estudios de prevalencia. OPS. Buenos Aires. (Nota técnica No 18). pp. 15-20.

Entrevista Personal con la Doctora Morella De Rosa. 2002. VIII Binacional Avícola, San Cristóbal, Venezuela.

Entrevista Personal con el Doctor Hernando Mateus R. 2002. Cúcuta.

Entrevista Personal con el Doctor Gersón Nieto S. 2002. Coordinador Centro de Diagnóstico ICA regional Cúcuta. Especialista en Anatomopatología.

Hernández, L. 2002. Caracterización epidemiológica de la enfermedad de Newcastle y Bronquitis infecciosa en codornices (Coturnix coturnix) en el área metropolitana de Cúcuta y municipios aledaños. Tesis de grado. U.F.P. S. 149 p. 
Prevalencia serológica la enfermedad de newcastle y bronquitis en codornices (Coturnix coturnix) en el Área Metropolitana de Cúcuta y municipios aledaños

Hofstad, M. 1988. Poultry disease. 8ªdition. lowa State University Press. 815 p.

Lancaster, J. E y Alexander D.J. 1966. Informe Anual del Departamento de Agricultura del Canadá. Monografía 3. pp. 12-18.

Lima, F.S., 2001. Estudio de parámetros clínicos, zootécnicos e inmunitarios de la vacunación contra la enfermedad de Newcastle en codornices (Coturnix coturnix japonica). - Facultad de Ciencias Agrarias y Veterinarias Campus de Jaboticabal, Universidad Estatal Paulista, Jaboticabal.

OIE - Oficina Internacional De Epizootias, 2002. Newcastle disease. In: Truszczynski, M. et al. International Animal Health Code - Mammals, Birds and Bees, 6.ed. Paris, p: 157-65.

Paulillo, A.C., 1982. Enfermedad de Newcastle. Estudio experimental de la respuesta inmune a las diferentes vacunas B1 y La Sota. Rev. Fac. Med. Vet. Zootec. Univ. São Paulo, 19: 9-43.

Paulillo, A.C. Y L. Doretto Junior, 2000. Enfermedad de Newcastle. In: Berchieri Júnior, A.; Macari, M.(Ed.) Enfermedades de las aves. 1.ed. Campinas: Fundação APINCO de Ciência e Tecnologia Avícolas, p: 267-81.

Villegas, P. 1990. Revisión de controles serológicos en avicultura. En: Avicultura Profesional. Abril. Vol. 7, No 4. pp. 154-158.

Villegas, P y Avellaneda G. 1992. Interpretación de resultados serológicos en Bronquitis Infecciosa. En: Avicultura Profesional. Enero. Vol. 10, N 1. pp. 8-12.

Revista Avicultores. 2002. Informe técnico 2001. CEISA. Marzo. Vol. 66. pp. 12-16.

Ziedler, K. and Hlinak, A. 1983. Detection of antibodies against Newcastle disease virus in wild birds. Berl Munich Tierarztl Wochenschr; 106(9). pp. 302-305.
Fecha recibido: Abril 18 de 2005

Fecha aceptado: Noviembre 25 de 2005 